\title{
MATLAB SIMULINK BASED DIGITAL PROTECTION OF TRANSFORMER
}

\author{
P.B.Thote ${ }^{1}$, M.B. Daigavane ${ }^{2}$, N.G. Bawane ${ }^{3}$ \\ ${ }^{1}$ Research Scholar, G.H.R.C.E, Nagpur (RTMNU, Nagpur), India \\ ${ }^{2}$ Principal, V.I.T, Nagpur (RTMNU, Nagpur), India \\ ${ }^{3}$ Principal, S.B.J.I.T.M.R, Nagpur (RTMNU, Nagpur), India
}

\begin{abstract}
Power transformer is one of the most important equipment in a power transmission and distribution system. This paper presents a technology to simulate differential relay in Matlab Simulink based environment for determining its behavior during various operating conditions. The results show that this simulation method can work properly and this will allow rapid modeling and testing of new algorithm in view to improve protection of transformer.
\end{abstract}

Keywords: differntial protection, magnetising inrush current, internal faults, over fluxing,trip signal $* * *$

\section{INTRODUCTION}

Transformer is a vital and expensive component of electrical power system. The unplanned outage of a power transformer is costly for utilities and hence need adequate protection [1]. It is necessary to study the various operating conditions of transformer to explore new protection algorithm [2].The aim of this paper is to simulate various conditions of a transformer like load condition, internal faults, abnormal conditions like magnetizing inrush current, over fluxing, etc. In this paper, the physical model of a two winding $230 \mathrm{~V} / 230 \mathrm{~V}$ is simulated in MATLAB-SIMULINK. The block parameters of transformer are obtained using experiment conducted on laboratory transformer. All the mentioned operating conditions are applied in this model one by one and are analyzed from differential protection point of view. An example presented in this paper demonstrates the capabilities and underline the advantages of Matlab-Simulink environment to study differential current pattern for various conditions which can be subsequently used for designing suitable digital relay. This data can be used to improve transformer protection using intelligent techniques.

\section{DEVELOPMENT OF DIGITAL DIFFERENTIAL}

\section{RELAY}

\subsection{Main Simulink Model}

The main simulink model used for obtaining differential current data is shown in Figure 1

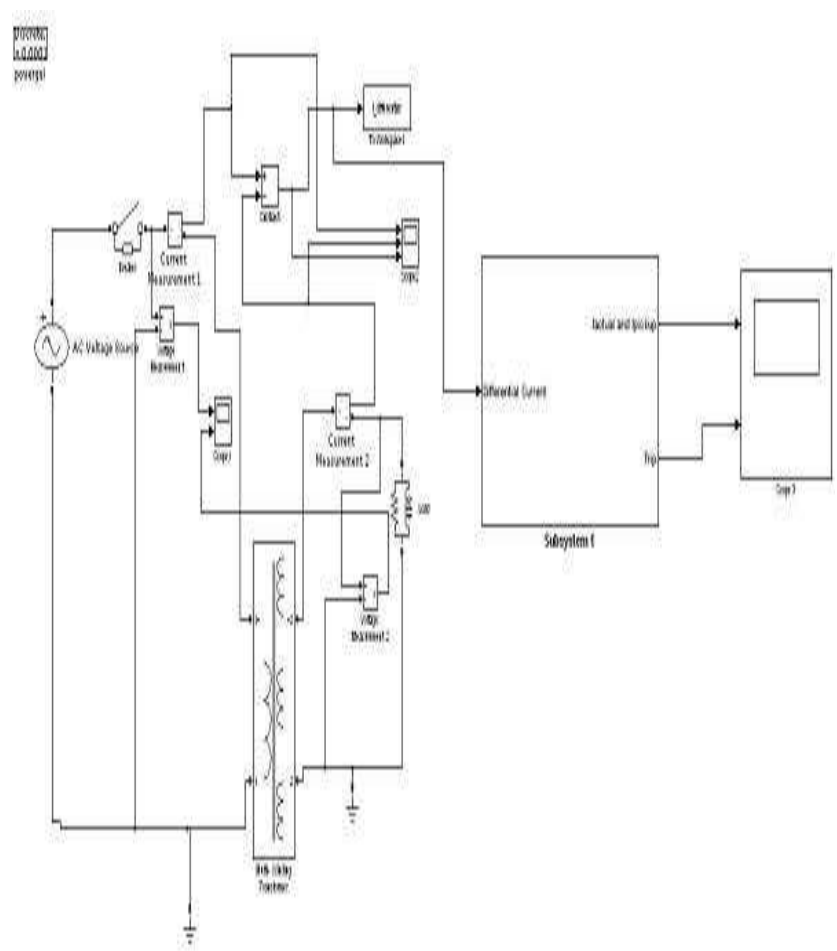

Fig 1 Simulink model for differential protection of Transformer

\subsection{Results of Laboratory Experiment}

To obtain the block parameters of transformer, open circuit and short circuit test is performed. Figure 2 shows the experimental set-up to obtain block parameters of transformer. 




Fig2. Experimental set-up

Figure 3 shows data entry window for two winding transformer.

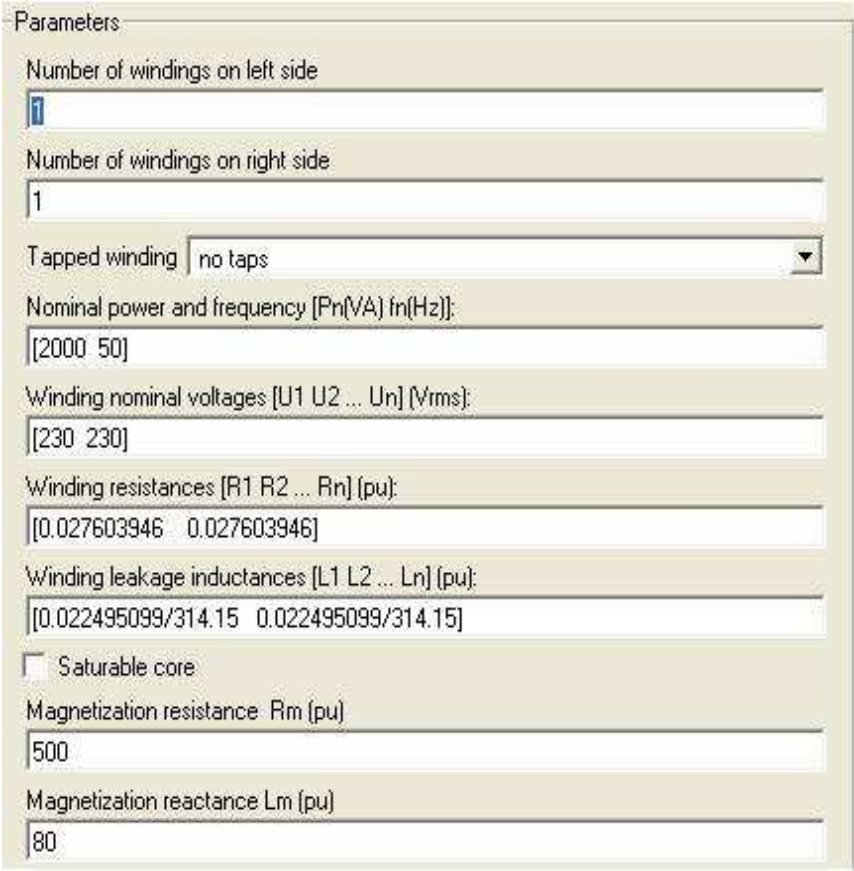

Fig3. Data entry window for two winding Transformer

\subsection{Validation of Simulink Model}

For load of $\mathrm{P}=1000 \mathrm{~W}$ and $\mathrm{Q}=800 \mathrm{VAr}, \mathrm{S}=1280.62 \mathrm{VA}$,

$\mathrm{I}_{1}=\mathrm{I}_{2}=5.56 \mathrm{~A}$ and $\mathrm{I}_{1 \text { peak }}=\mathrm{I}_{2 \text { peak }}=7.87 \mathrm{~A}$

The waveforms obtained by this simulink model are in line with the actual calculations as shown in figure 4 .
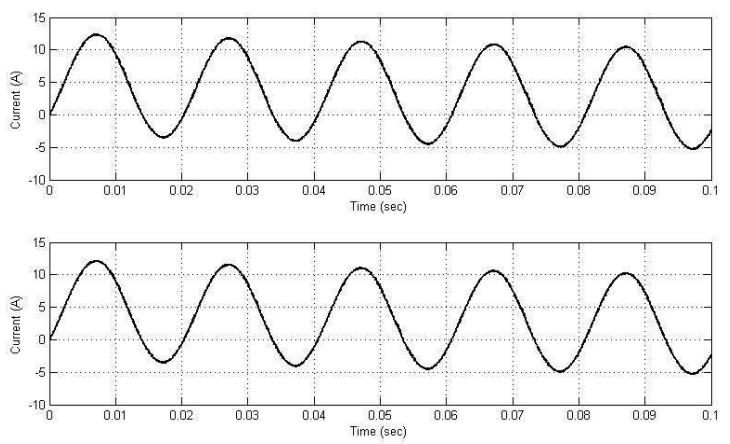

Fig 4 Winding currents on two sides of a Transformer

This confirms the correctness of the simulink model and hence data of differential current for various operating conditions obtained from this model can be used for further analysis. The pickup value of differential current is set equal to $0.35 \mathrm{~A}$.

\subsection{Subsystems used in Main Simulink Model}

Figure 5 illustrates the components of subsystem 1 used in main simulink model where differential current is input and Trip signal is the output.

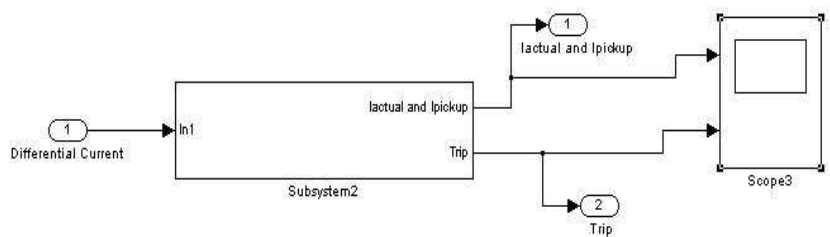

Fig 5 Sub-system 1 used in main simulink model

Figure 6 shows the components of subsystem 2 .

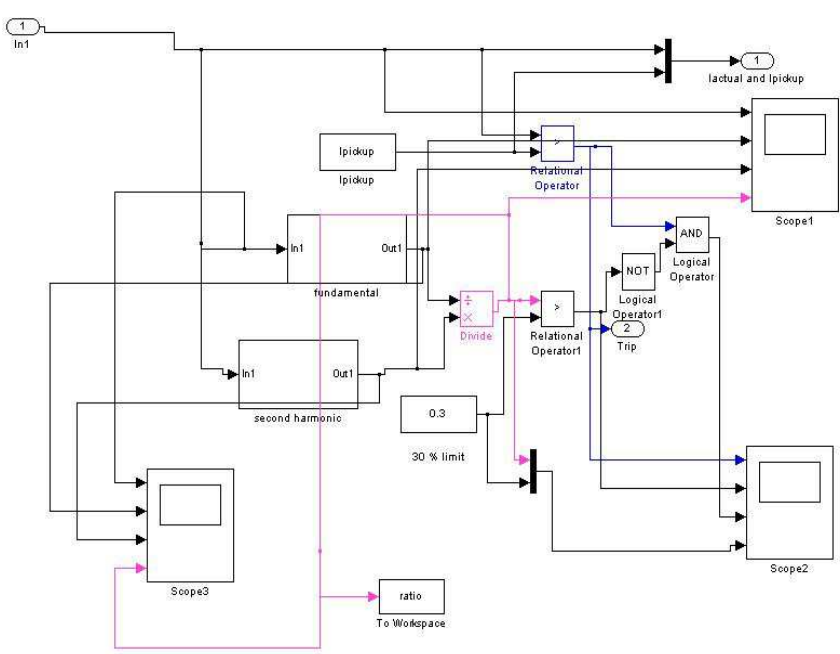

Fig 6 Sub-system 2 used in main simulink model 
The relational operator determines whether the differential current is more than the peak up value of current. Fundamental and second harmonic block calculates the fundamental and second harmonic contents of differential current. Divide block calculates the ratio of second harmonic to fundamental component. Relational operator 1 block determines whether the ratio is more than the set limit of ratio. Not block and And block realizes harmonic restrain scheme.

\section{RESULTS AND DISCUSSION}

The results are given for following conditions of energisation and faults.

\subsection{Normal Operation}

When the transformer is operating normally, the differential current is well below the peak up value and the relay does not issue any trip signal as shown in Figure 7.It is the correct operation of relay.


Fig 7 Differential current and Trip signal for normal condition

\subsection{Internal Fault}

When few turns of the windings are shorted, the differential current exceeds the peak up value and the relay issues trip signal as shown in figure 8.It is again the correct operation of ralay.Various internal faults on winding 1 and 2 of transformer are simulated by changing number of turns. The fault occurs at $0.02 \mathrm{sec}$.
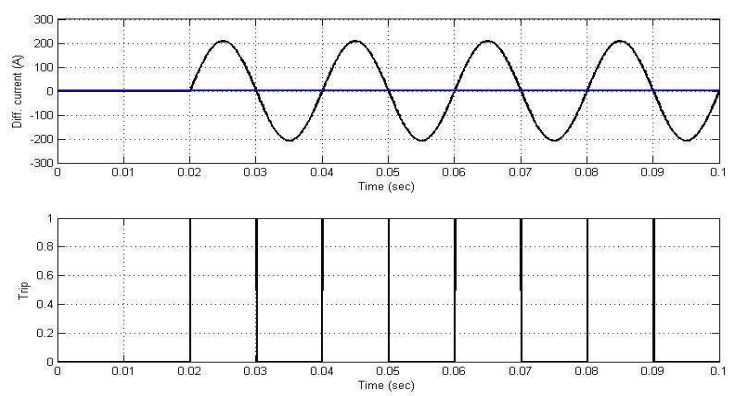

Fig 8 Differential current and Trip signal for internal fault condition
In this case, the differential current is more than pick-up value and relay will operate. It is the correct operation of relay.

\subsection{Magnetizing Inrush Current}

The transient magnetizing current of a transformer flowing after connecting the transformer with AC source is called inrush current. Inrush current is highly asymmetric. It results from saturation of core of transformer caused by excessive growth of magnetic flux in one direction only. The first peak of an inrush current may exceed many times the value of transformer nominal current. Fig. 9 shows the waveform of a magnetizing inrush current with transformer energized at instant zero on the input voltage wave.

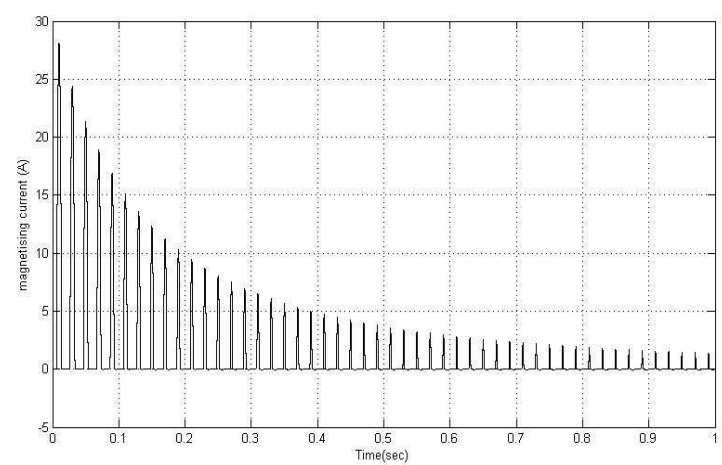

Fig 9 Magnetizing inrush current

It is possible to analyze the various factors which affect the first peak of the inrush current like saturation characteristics of the core, instant on input voltage wave where transformer is energized, residual magnetic flux, etc in the simulation presented in this paper.

Since the differential current is above the pickup value of current, the relay issues trip signal as shown in fig 10 .
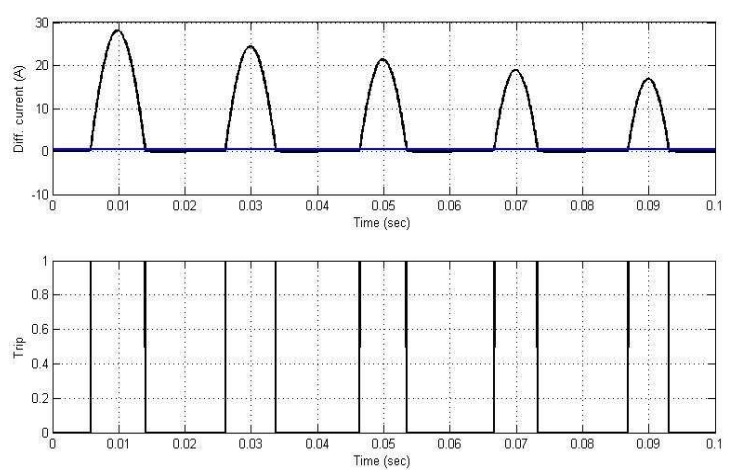

Fig 10 Differential current and Trip signal for Magnetizing inrush condition 
During this condition the relay mal-operates. Conventionally, second harmonic blocking scheme is used for discrimination between inrush current and fault current. But today's new low loss core material decreases the second harmonic component of inrush current [3]. Therefore, researchers are using new techniques like wave shape recognition, Digital Signal Processing based techniques for accurate and rapid discrimination between abnormal and fault conditions [4, 5]. For the past few years, inrush current became an interesting topic and many researchers have focused their studies in this matter [6].

\subsection{Over Fluxing Condition}

Increase in input voltage causes increase in working flux level. The reduction in supply frequency also increases the core flux. The generator transformers are more prone for over fluxing as this may be subjected to an uncomfortable combination of over voltage and under frequency during start-up. The ratio of V/f is an index of over fluxing. Fig.11 shows differential current data for the over fluxing condition when input voltage $=282 \mathrm{~V}$ and input frequency $=47 \mathrm{~Hz}$ which results in mal operation of relay.
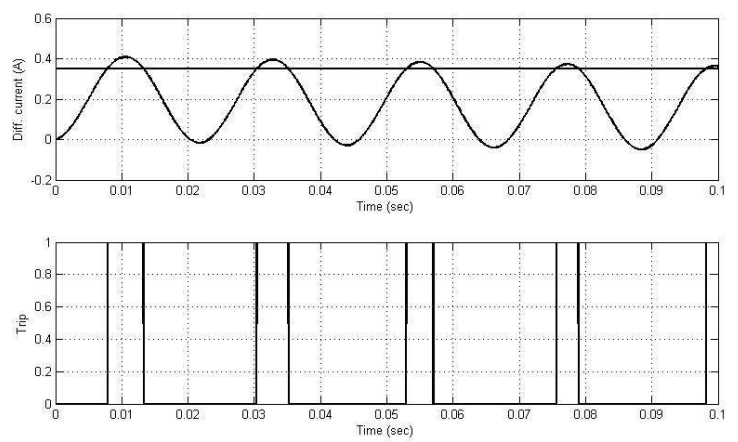

Fig 11 Differential current and Trip signal for overfluxing condition

\section{CONCLUSIONS}

The results presented in this paper are in line agreement with the theoretical calculations. From the work presented in this paper, it is possible to obtain differential current data for various operating conditions which can be used for improving the protection function of transformer, mainly to discriminate between transformer internal faults and transients like inrush, over fluxing conditions.

\section{REFERENCES}

[1] S.V.Kulkarni,S.A.Khaparde, Transformer Engineering. Design and Practice, Marcel Dekker Inc., New York, Basel, 2004.

[2] Haihui Song, Fangming Zhao, Di He, "Simulation study on internal fault of Transformer " Elsevier, sciverse science direct, 2012 international conference on solid state devices and material science, Physics Procedia 25 (2012) pp 459-464

[3] J.P Patra, "A discussion on power transformer magnetizing inrush, remedy, fault detection in Matlabsimulink environment", International Journal of Electrical Engineering, ISSN 0974-2158 vol.4, number 1 (2011), pp 83-102

[4] R. Bouderbala, H. Bentarzi and A. Ouadi, "Digital Differential Relay Reliability Enhancement of Power Transformer", International Journal of Circuits, System And Signal Processing

[5] M.S. El-Bages, "Improvement of Digital Differential Relay Sensitivity For Internal Ground Faults In Powertransformers ", IJPTE Journal, ISSN 2077-3528, pp 1-5

[6] P.L,Mao and R.K.Aggarwal, "A wavelet transform based decision making logic method for discrimination between internal faults and inrush currents in power transformers", International journal of Electric power and Energy systems, Vol. 22, no 6 ,pp-389-395 2000

[7] A.I.Megahed, A.Ramadan, W.El.Mahdy, "Power transformer differential relay using wavelet transform energies", in:Power and Energy Society General Meeting, IEEE, 20-24,1-6,2008

\section{REFERENCES:}

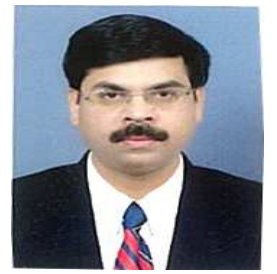

Pankaj B. Thote has born in Nagpur (Maharashtra)in 1975. He received the B.E. degree in Electrical Engineering in 1997 and M.E. degree in Electrical Power System in 2010 from Sant Gadge Baba Amravati University, India. $\mathrm{He}$ is currently working as a Assistant Professor \& Head in Electrical Engineering Department of Shri Shantilalji Badjate Institute of Technology, Managment and Research, Nagpur. His research interests include network analysis and protection. He is a Life Member of the Indian Society for technical Education. He is pursuing his Ph.D degree from Rashtrasanth Tukdoji Maharaj Nagpur University.

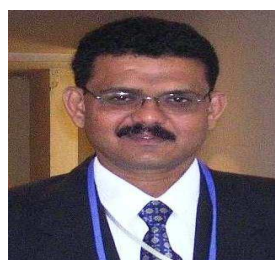

Dr. Manoj B. Daigavane obtained the B.E. Degree in Power Electronics Engineering from Nagpur University, India in 1988. He received the M.S. Degree in Electronics and Control Engineering from Birla Institute of Technology and Science, Pilani (Raj) India in 1994. He also obtained the M.E. Degree in Power Electronics Engineering from Rajeev Gandhi University of Technology, Bhopal (M.P), India in 2001. He received Ph D Degree in Electrical Engineering from R.T.M. Nagpur University, India in 2009. Since Sept.1988- June 2007, he had been with the Department of Electronics and Power Electronics Engineering, B. D. College of Engineering, Sewagram (Wardha), affiliated to the Nagpur University, India. Since July 
1, 2007 to Apr 30, 2009, he was Professor \& Head of Electrical and Electronics Engineering, Disha Institute of Mgmt. and Tech., Raipur (C.G.) where he is engaged in teaching \& research. Earlier, he was Principal at S. D. College of Engineering, Wardha. Presently, he is Principal of V.I.T College of Engineering, Nagpur - Maharashtra (India). His main areas of interest are resonant converters, Power quality issues, DSP applications and Power electronics for motor drives. He has been responsible for the development of Electrical Machines and Power Electronics Laboratories He is a Member of the Institution of Engineers (India) and a Life Member of the Indian Society for technical Education.

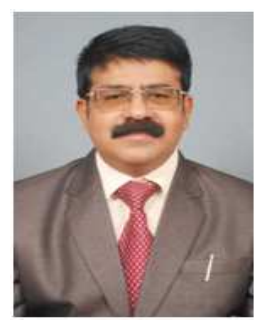

Dr. Narendra G. Bawane is a Professor \& Principal of S. B. Jain Institute of Technology, Management \& Research, Nagpur. Prior to this assignment, he was Head of Computer Science and Engineering department at G. H. Raisoni college of Engineering, Nagpur. He has also worked with B.D. College of engineering sewagram and Govt. Polytechnic, Nagpur for several years. He is having total teaching experience of more than 24 years to his credit. He has completed his B.E. from Nagpur University in 1987 and M. Tech. in 1992 from IIT, New Delhi. He completed his Ph. D. in 2006 at VNIT, Nagpur. His areas of interest are ANN,Fuzzy,Embeded Systems etc. 